\title{
Preparation of photonic-magnetic responsive molecularly imprinted microspheres and their application to fast and selective extraction of $17 \beta$-estradiol
}

\author{
Hailong Peng ${ }^{\mathrm{a}, \mathrm{b}}$, Mei Luo ${ }^{\mathrm{a}, \mathrm{b}}$, Hua Xiong ${ }^{\mathrm{b}, *}$, Ningxiang Yu ${ }^{\mathrm{b}}$, Fangjian Ning ${ }^{\mathrm{b}}$, Jieping Fan ${ }^{\mathrm{a}}$, \\ Zheling Zeng ${ }^{\mathrm{a}}$, Jinhua $\mathrm{Li}^{\mathrm{c}}$, Lingxin Chen ${ }^{\mathrm{c}, *}$ \\ a School of Resources, Environmental, and Chemical Engineering, Nanchang University, Nanchang 330031, China \\ b State Key Laboratory of Food Science and Technology, Nanchang University, Nanchang 330047, China \\ ${ }^{c}$ Key Laboratory of Coastal Environmental Processes and Ecological Remediation, Yantai Institute of Coastal Zone Research, Chinese Academy of Sciences, \\ Yantai 264003, China
}

\section{A R T I C L E I N F O}

\section{Article history:}

Received 14 December 2015

Received in revised form 27 February 2016

Accepted 2 March 2016

Available online 4 March 2016

\section{Keywords:}

Molecularly imprinted polymers

Photonic responsive

Magnetic separation

$17 \beta$-Estradiol

\begin{abstract}
A B S T R A C T
Photonic-magnetic responsive molecularly imprinted microspheres (PM-MIMs) were prepared by seed polymerization, through suitable functionalization of magnetic nanoparticles for further coating with photoresponsive functional monomer and imprinted layers, and then were successfully applied to the fast and selective extraction of $17 \beta$-estradiol $\left(17 \beta-E_{2}\right)$ from real samples. The PM-MIMs possessed a sandwich micro-spherical structure containing $\mathrm{Fe}_{3} \mathrm{O}_{4}$ core, $\mathrm{SiO}_{2}$ middle layer, and MIPs shell with thickness of $25 \mathrm{~nm}$. The PM-MIMs displayed excellent photoresponsive properties and could be rapidly separated from solutions under an external magnet. The PM-MIMs had specific affinity towards $17 \beta-\mathrm{E}_{2}$ with high adsorption capacity $\left(Q_{\max }=0.84 \mathrm{mg} \mathrm{g}^{-1}\right)$ and fast binding kinetics $\left(K_{\mathrm{d}}=26.08 \mathrm{mg} \mathrm{L}^{-1}\right)$. The PM-MIMs proved to be an ideal photoswitch with the ability of reversible uptake and release of $17 \beta-E_{2}$ upon alternate 365 and $440 \mathrm{~nm}$ irradiation: $45.0 \%$ of $17 \beta-\mathrm{E}_{2}$ released from the PM-MIMs upon $365 \mathrm{~nm}$ irradiation, and $94.0 \%$ of the released $17 \beta-\mathrm{E}_{2}$ was rebound to the PM-MIMs at $440 \mathrm{~nm}$. Accordingly, the PM-MIMs were applied for fast separation and extraction of $17 \beta-\mathrm{E}_{2}$ followed by HPLC-UV determination, presenting the low limit of detection (LOD, $S / N=3$ ) and quantification ( $L O Q, S / N=10$ ) of 0.18 and $0.62 \mu \mathrm{mol} \mathrm{L}^{-1}$, respectively. The high recoveries for spiked milk powder and drinking water samples were in the range of $97.5-113.0 \%$ with relative standard deviations less than $4.4 \%$. This study reasonably combined photonic response, magnetic separation and surface imprinting, which endowed the PM-MIMs with significant advantages of high adsorption capacity and fast binding kinetics, convenient separation and recycled use, and simple rapid eco-benign adsorption/elution processes for template molecules. Thus, the PM-MIMs based method may be a simple, rapid, convenient, cost-effective and environmentally-friendly way for simultaneous separation, enrichment and detection of trace $17 \beta-\mathrm{E}_{2}$ in complicated matrices.
\end{abstract}

(C) 2016 Elsevier B.V. All rights reserved.

\section{Introduction}

The more and more serious pollution of environmental estrogens (EEs) in foods and water has received considerable concerns $[1,2]$. Amongst the EEs, $17 \beta$-estradiol $\left(17 \beta-E_{2}\right)$ is quite important, and has been widely used in environment and foods owing to its potent curative effects $[3,4]$. However, the illegal addition and abuse of $17 \beta-E_{2}$ leads to its accumulation in body through food chains, and then causes series toxic side effects, such as damaging

\footnotetext{
* Corresponding author.

E-mail addresses: huaxiong100@126.com (H. Xiong), lxchen@yic.ac.cn (L. Chen).
}

endocrine system, disrupting activity of body, and inducing cancer [5]. It has been reported that such EEs can cause biological effects of model animals even at much lower the regulated safe dose levels [6]. Moreover, the complicated matrix effects of samples make residue detection of $17 \beta-\mathrm{E}_{2}$ face crucial challenges. Therefore, it is urgently required to develop simple, fast, and convenient methods for highly selective separation, enrichment and high sensitive detection of $17 \beta-E_{2}$.

Among the available methods for $17 \beta-E_{2}$, enzyme linked immunosorbent assay (ELISA) [7], high performance liquid chromatography (HPLC) [8], liquid chromatography-mass spectrometry (LC-MS) [9], and gas chromatography-mass spectrometry (GC-MS) [10], are the most frequently used ones, along with necessary pre- 


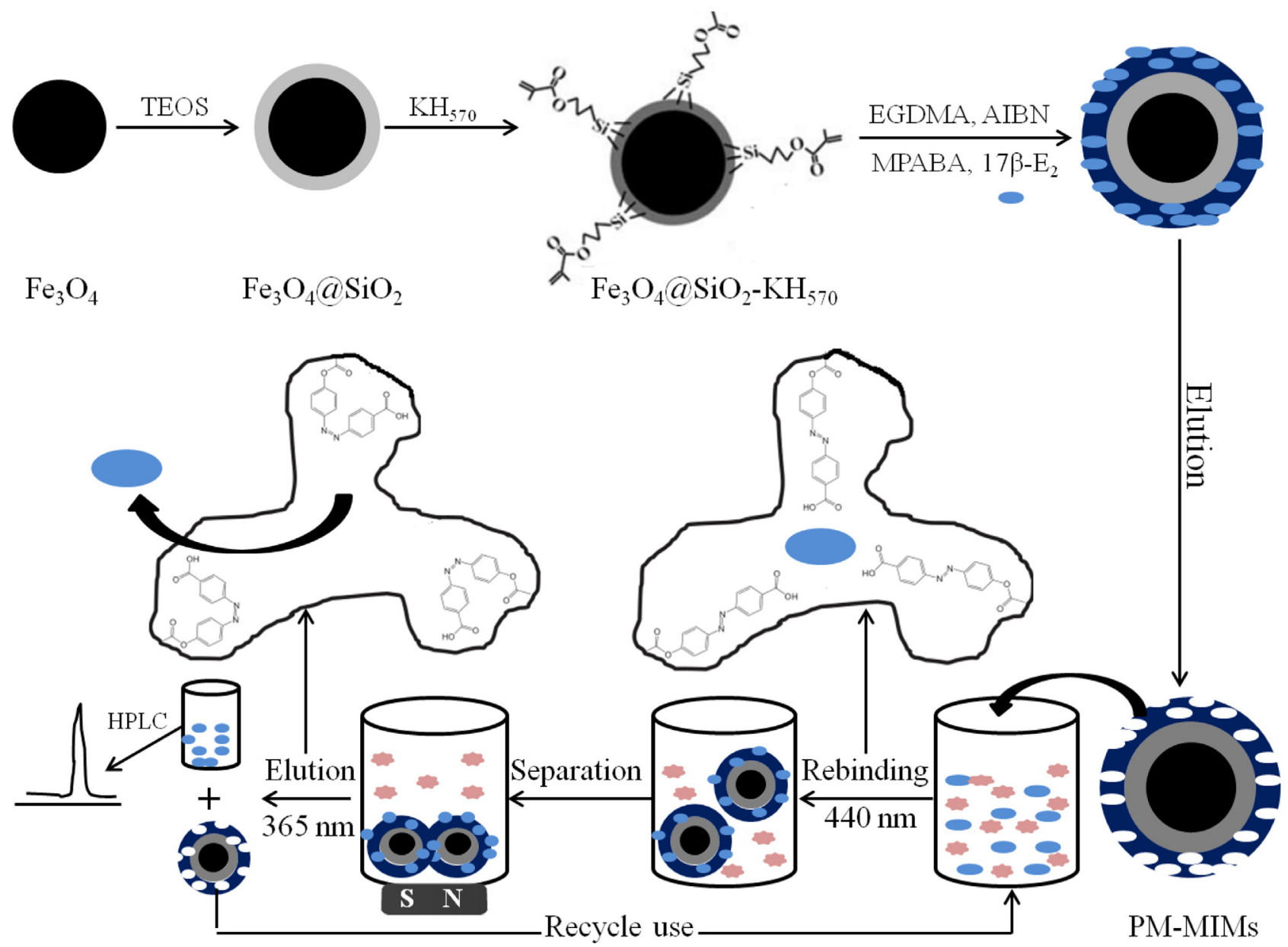

Fig. 1. Schematic illustration for the preparation process of the PM-MIMs, possible mechnism of photoregulatd uptake and release and the extraction procedure.

treatment processes, such as solid phase extraction (SPE) and solid phase microextraction (SPME). However, the traditional extraction sorbents of SPE usually exhibit low selectivity, which leads to low adsorption capacity and enrichment efficiency. Thus, developing specific sorbents with high selectivity is imperative. As a kind of promising material with desirable selectivity, physical robustness, thermal stability, molecularly imprinted polymers (MIPs) have become increasingly popular in sample pretreatment, chromatographic separation and chemical/biological sensing fields [11,12]. Recently, a number of studies on MIPs-based SPE for enrichment and detection of $17 \beta-E_{2}$ have been reported [12-20]. However, the potential application of traditional MIPs has also been significantly limited due to these drawbacks of complicated after-treatment workup, heterogeneous binding sites, low mass transfer, and difficult separation from solutions. So, it is very important to develop novel MIPs in order to overcome the drawbacks of traditional MIPs.

Meanwhile, as is well known, stimuli-responsive polymers (SRPs) can significantly change their physicochemical properties such as molecular chain structure, shape, surface structure, optical properties and electrical properties to external stimuli such as light, temperature, magnetism and $\mathrm{pH}[21]$. In recent years, the combination of SRPs with MIPs as a new method has been developed, which integrates the advantages of MIPs and SRPs [22]. That is, the resultant stimuli-responsive MIPs (SR-MIPs) act like a switch with the ability of reversible uptake and release of template/target molecules upon alternate external stimuli [23]. Till now, various SR-MIPs have been prepared, such as $\mathrm{pH}$ [24], temperature [25,26], photonic [27,28], and magnetic [29,30] ones. Among these external stimuli factors, photoirradiation is one of the most frequently used external stimuli for SR-MIPs due to its convenience to apply, easiness to control, and superior cleaning [31,32]. Azobenzene is widely applied as the chromophore of photoresponsive SR-MIPs because they exhibit excellent photoinduced fast and reversible isomerization between the trans- and cis-isomers of the azomoieties [33,34]. A variety of azobenzene-based SR-MIPs have been developed with different morphologies such as bulk monoliths [35], bulk hydrogels [36], and microspheres [37]. Meanwhile, photoresponsive SR-MIPs together with thermo-, and $\mathrm{pH}$-responsive properties, have been also reported [38,39]. However, these photoresponsive SR-MIPs dispersed in solution are difficult to separate via traditional centrifugation and filtration methods. Interestingly, the combination of magnetic separation with SR-MIPs can deal with the abovementioned problems. We have developed magnetic-photonic SR-MIPs for separation and detection of caffeine in water samples [40]. However, the magnetic nanoparticles have not been functionalized by active groups, and it is difficult to further polymerize with functional monomers, resulting in irregular structures unfavorable to imprinting performances. Thus, it is necessary to functionalize magnetic nanoparticles for developing ideal magnetic SR-MIPs. Meanwhile, to the best of our knowledge, no photonic-magnetic responsive SR-MIPs have been reported for separation, enrichment and detection of $17 \beta-\mathrm{E}_{2}$.

Thus, in this work, magnetic nanoparticles $\left(\mathrm{Fe}_{3} \mathrm{O}_{4}\right)$ were synthesized and functionalized with vinyl double bonds, and the self-synthesized 4-[(4-methacryloyloxy) phenylazo]benzoic acid (MPABA) containing azobenzene structure was used as photoswitchable functional monomer, for the preparation of photonic-magnetic responsive molecularly imprinted micro- 

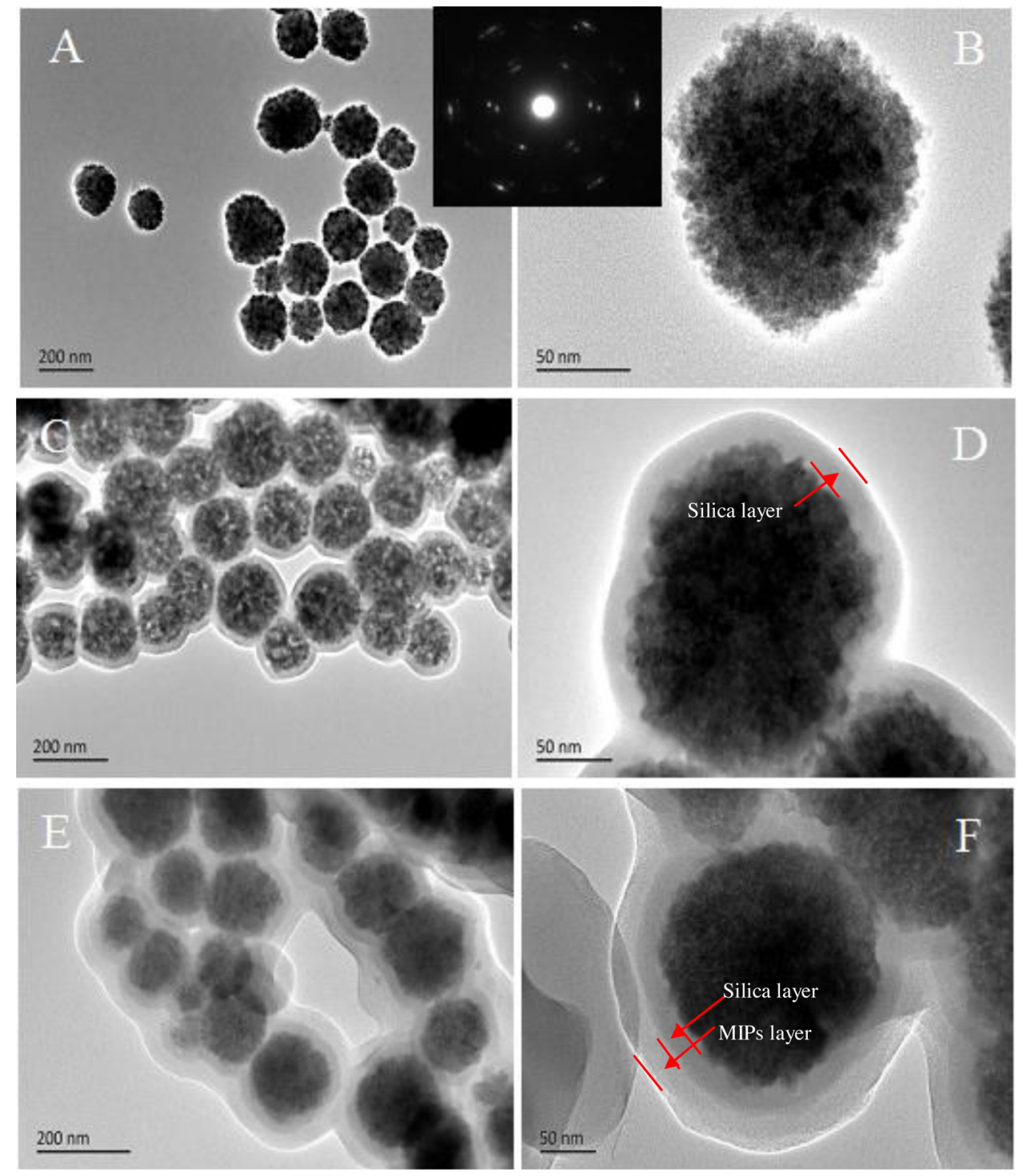

Fig. 2. TEM images of the $\mathrm{Fe}_{3} \mathrm{O}_{4}(\mathrm{~A}$ and $\mathrm{B}), \mathrm{Fe}_{3} \mathrm{O}_{4} @ \mathrm{SiO}_{2}(\mathrm{C}$ and $\mathrm{D})$, and PM-MIMs (E and $\mathrm{F}$ ).

spheres (PM-MIMs) and application to the fast and selective extraction of $17 \beta-E_{2}$. The PM-MIMs retained the photoisomerization properties of azobenzene chromophore and were responsive to an external magnetic field. The photo-regulated uptake and release of trace $17 \beta-E_{2}$, magnetic separation, and binding properties of the PM-MIMs were systematically investigated. Furthermore, the PMMIMs were successfully applied to the extraction of $17 \beta-E_{2}$ in milk powder and drinking water samples, which indicated a great potential for the analysis/removal of the EEs in complicated samples.

\section{Experimental}

\subsection{Reagents and materials}

Hexahydrate ferric chloride $\left(\mathrm{FeCl}_{3} \cdot 6 \mathrm{H}_{2} \mathrm{O}\right)$, trisodium citrate, ethylene glycol, sodium acetate, and acetonitrile were purchased from Xilong Chemical Co., Ltd. (Shantou, China). Tetraethoxysilane (TEOS), 3-(methacryloxyl) propyltrimethoxysilane $\left(\mathrm{KH}_{570}\right), 2,2^{\prime}$ azobis(isobutyronitrile) (AIBN), ethylene glycoldimethacrylate (EGDMA), 17-beta-estradiol (17 $\beta$-E 2$), 17$-alpha-estradiol $\left(17 \alpha-\mathrm{E}_{2}\right)$, estrone $\left(E_{1}\right)$, and estriol $\left(E_{3}\right)$ were all purchased from Aladdin (Shanghai, China). Other affiliated reagents such as dimethylsulfoxide (DMSO) and acetonitrile (ACN) were all obtained from Sinopharm Chemical Reagent Co., Ltd. (Shanghai, China). All the reagents were of analytical grade and used without further purification. Ultrapure water used throughout the work was produced by a Milli-Q Ultrapure Water System with the water outlet operating at $18.2 \mathrm{M} \Omega$ (Millipore, Bedford, MA, USA).

\subsection{Synthesis of $\mathrm{Fe}_{3} \mathrm{O}_{4}$ nanoparticles}

$\mathrm{FeCl}_{3}(1.05 \mathrm{~g})$, trisodium citrate $(0.6 \mathrm{~g})$, and sodium acetate (3.6 g) were dissolved in ethylene glycol $(60 \mathrm{~mL})$ under vigorous stirring for $30 \mathrm{~min}$ at room temperature. The mixture was sealed in a poly(tetrafluoroethylene) (Teflon)-lined autoclave $(100 \mathrm{~mL}$ capacity) and heated at $200^{\circ} \mathrm{C}$ for $10 \mathrm{~h}$, and then cooled to room temperature. The black products $\left(\mathrm{Fe}_{3} \mathrm{O}_{4}\right.$ nanoparitcles) were collected by a magnet, washed with ethanol and ultrapure water for several times, and dried at $60^{\circ} \mathrm{C}$ for further use. 

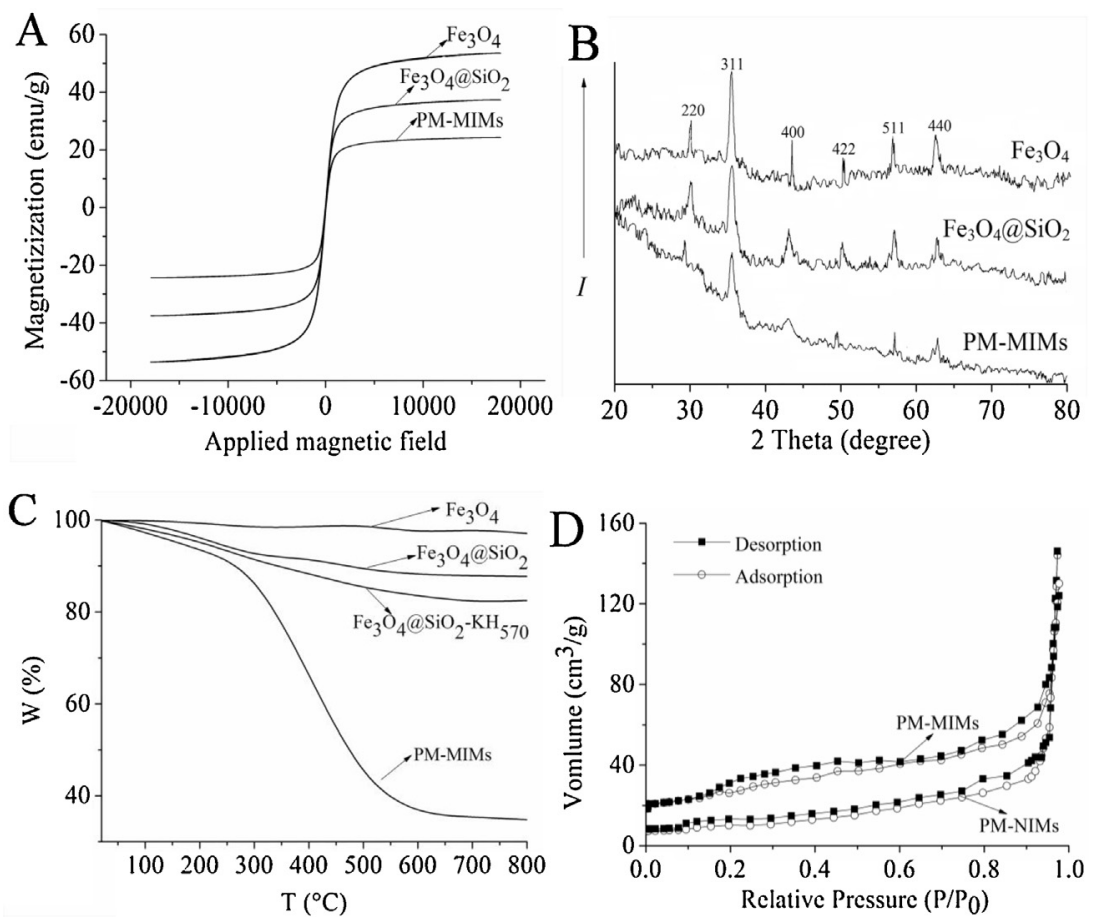

Fig. 3. Characterizations of the PM-MIMs. (A) Hysteresis loops, (B) XRD patterns, (C) TGA curves, and (D) $\mathrm{N}_{2}$ adsorption-desorption isotherms.

\subsection{Synthesis of $\mathrm{Fe}_{3} \mathrm{O}_{4} @ \mathrm{SiO}_{2}-\mathrm{KH}_{570}$}

The prepared $\mathrm{Fe}_{3} \mathrm{O}_{4}$ nanoparticles ( $50 \mathrm{mg}$ ) were dispersed into a mixed solution containing ethanol $(160 \mathrm{~mL})$, ultrapure water $(40 \mathrm{~mL})$, and ammonia aqueous solution $(2.24 \mathrm{~mL}, 25 \mathrm{wt} \%)$, and sonicated for $20 \mathrm{~min}$. TEOS $(1.0 \mathrm{~mL})$ was added to the dispersion mixture and stirred for $6 \mathrm{~h}$ at $30^{\circ} \mathrm{C}$. The obtained $\mathrm{Fe}_{3} \mathrm{O}_{4} @ \mathrm{SiO}_{2}$ nanoparticles were washed with ethanol and ultrapure water for removing the blank silica nanoparticles. For functionalizing with vinyl double bonds, $\mathrm{Fe}_{3} \mathrm{O}_{4} @ \mathrm{SiO}_{2}$ nanoparticles and $\mathrm{KH}_{570}$ dispersed into anhydrous ethanol, and reacted for $48 \mathrm{~h}$ with stirring under nitrogen atmospheres. The resultants nanoparitcles were isolated by magnet and washed with acetic acid for removing the unreacted $\mathrm{KH}_{570}$. The functionalized nanoparticles were obtained with vinyl bonds on $\mathrm{Fe}_{3} \mathrm{O}_{4} @ \mathrm{SiO}_{2}$ surface $\left(\mathrm{Fe}_{3} \mathrm{O}_{4} @ \mathrm{SiO}_{2}-\mathrm{KH}_{570}\right)$

\subsection{Preparation of the PM-MIMs}

$17 \beta-E_{2}$ imprinted PM-MIMs were prepared by seed polymerization. MPABA was firstly synthesized according to our previous work [40] and then was used as the photoresponsive functional monomer for the PM-MIMs preparation. Briefly, template (17 $\beta$ $\mathrm{E}_{2}, 1 \mathrm{mmol}, 0.272 \mathrm{~g}$ ) and photoresponsive functional monomer (MPABA, $6 \mathrm{mmol}, 1.86 \mathrm{~g}$ ) were dissolved in the mixture solutions (DMSO-ACN, $50 \mathrm{~mL}$ ) and stored for $24 \mathrm{~h}$. The above-prepared $\mathrm{Fe}_{3} \mathrm{O}_{4} @ \mathrm{SiO}_{2}-\mathrm{KH}_{570}(500 \mathrm{mg}$ ), crosslinker (EGDMA, $6.8 \mathrm{mmol}$ ), and initiator (AIBN, $30 \mathrm{mg}$ ) were mixed in toluene $(10 \mathrm{~mL})$ by sonication for 30 min followed by addition of the above solutions of $17 \beta-E_{2}$ and MPABA. And then the mixture solutions were stirred at $70^{\circ} \mathrm{C}$ for $24 \mathrm{~h}$ under nitrogen condition for polymerization. The products, i.e., PM-MIMs, were separated by the external magnet and eluted with methanol/acetic acid $(9: 1, v / v)$ in a Soxhlet extractor until no template detected, and dried under vacuum for $24 \mathrm{~h}$. The whole syntheses procedures were carried out in the dark condition. As the control, photonic-magnetic responsive non-imprinted microspheres (PM-NIMs) were prepared using the same processes without addition of the template $17 \beta-\mathrm{E}_{2}$.

\subsection{Characterization}

The morphological evaluation was performed by JEOL transmission electron microscope (TEM) (JEM-2010HR, Japan). The magnetic properties were examined by vibrating specimen magnetometer (VSM) (7407, Lakeshore, USA). The X-ray diffractometer (XRD) patterns were recorded using XRD analyzer (D8-FOCUS, Bruker, Karlsruhe, Germany). Thermal gravimetric analyses (TGA) were carried out on a differential scanning calorimeter (SDT-Q600 , TGA-DSC, TA instruments, USA). $\mathrm{N}_{2}$ adsorption-desorption isotherms were obtained via Brunauer-Emmett-Teller (BET) analysis on Beishide instruments (3H-2000, Beijing, China). Spectroscopic characterization of the MPABA and PM-MIMs were scanned by a UV/Vis spectrometer (TU-1901, Beijing, China). Chromatographic analysis was carried out on a HPLC-UV instrument (Agilent Technologies 1260 Infinity) under the optimized conditions: injection volume, $20 \mu \mathrm{L}$; mobile phase, acetonitrile/ultrapure water $(7: 3, \mathrm{v} / \mathrm{v})$; flow rate, $1.0 \mathrm{~mL} \mathrm{~min}^{-1}$; detection wavelength, $208 \mathrm{~nm}$; column, $250 \mathrm{~mm} \times 4.6 \mathrm{~mm} \mathrm{C}_{18}$ at room temperature.

\subsection{Adsorption experiments}

Static adsorption experiments were carried out in DMSO-ACN solutions in the dark. $20 \mathrm{mg}$ of the PM-MIMs or PM-NIMs samples were dispersed in a $10-\mathrm{mL}$ flask containing $2.0 \mathrm{~mL} 17 \beta-\mathrm{E}_{2}$ solutions of various concentrations. After shaking for $12 \mathrm{~h}$ at room temperature, the samples were separated by an external magnet. The free concentration of $17 \beta-E_{2}$ in the supernatant solutions was determined by HPLC. The adsorption amount of the PM-MIMs was calculated by subtracting the residual amount of templates in solution from the total amount of templates. Each group of experiments was carried out three times in parallel.

The binding kinetics study was performed as the following process. The PM-MIMs or PM-NIMs $(20 \mathrm{mg})$ were dispersed into $17 \beta-E_{2}$ solutions $(40 \mu \mathrm{M})$ and incubated at room temperature for different time in the dark. The PM-MIMs were then separated by external magnetic field and the free $17 \beta-\mathrm{E}_{2}$ concentration of 

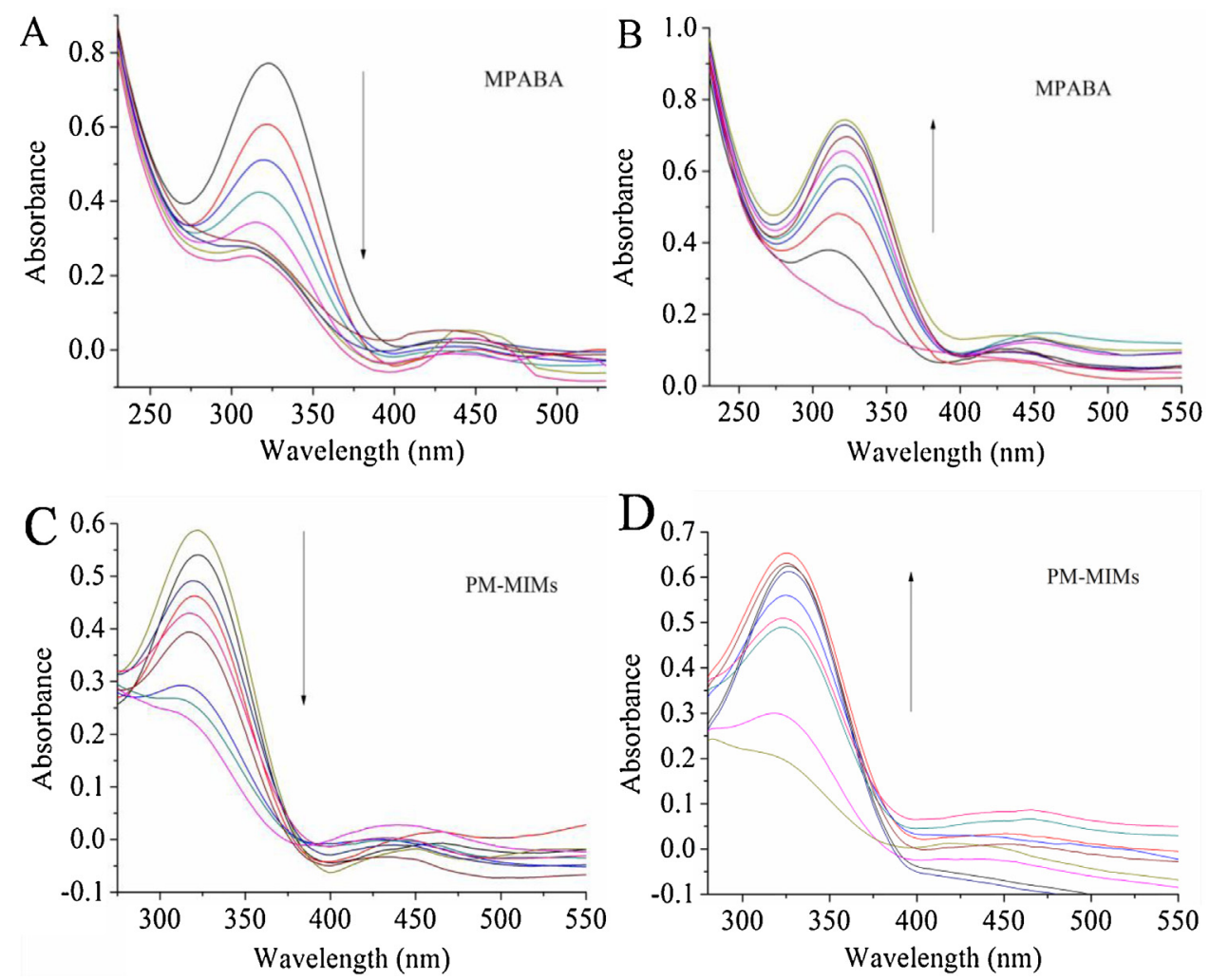

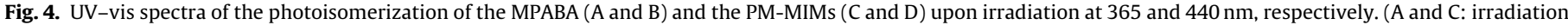
at $365 \mathrm{~nm}$ for $0,10,20,30,40,50,60,75$, and $90 \mathrm{~min}$; B and D: irradiation at $440 \mathrm{~nm}$ for $0,10,20,30,40,50,60,75$, and $90 \mathrm{~min}$ ).

Table 1

Static adsorption fitting data of the PM-MIMs and PM-NIMs.

\begin{tabular}{|c|c|c|c|c|}
\hline Isotherm model & Equation & Parameter & PM-MIMs & PM-NIMs \\
\hline \multirow[t]{3}{*}{ Langmuir $^{\mathrm{a}}$} & \multirow[t]{3}{*}{$C_{\mathrm{e}} / Q_{\mathrm{e}}=\left(1 / Q_{\max }\right) C_{\mathrm{e}}+1 /\left(K_{\mathrm{L}} Q_{\max }\right)$} & $R^{2}$ & 0.978 & 0.993 \\
\hline & & $Q_{\max }(\mathrm{mg} / \mathrm{g})$ & 0.820 & 0.182 \\
\hline & & $K_{\mathrm{L}}(\mathrm{L} / \mathrm{g})$ & 0.040 & 0.117 \\
\hline \multirow[t]{3}{*}{ Freundlich ${ }^{\mathrm{b}}$} & $\ln$ & $R^{2}$ & 0.997 & 0.982 \\
\hline & $Q_{e}=1 / n$ & $K_{\mathrm{F}}(\mathrm{mg} / \mathrm{g})$ & 0.034 & 0.021 \\
\hline & $\ln$ & $1 / \mathrm{n}$ & 0.830 & 0.650 \\
\hline \multirow[t]{3}{*}{ Scatchard ${ }^{c}$} & \multirow{3}{*}{$\begin{array}{l}Q_{\mathrm{et}}+\mathrm{Ql}_{\mathrm{l}}=\left(Q_{\max }-Q_{\mathrm{e}}\right) / K_{\mathrm{d}} \\
K_{\mathrm{F}}\end{array}$} & $R^{2}$ & 0.918 & 0.907 \\
\hline & & $Q_{\max }(\mathrm{mg} / \mathrm{g})$ & 0.842 & 0.192 \\
\hline & & $K_{\mathrm{d}}(\mathrm{mg} / \mathrm{L})$ & 26.08 & 9.414 \\
\hline
\end{tabular}

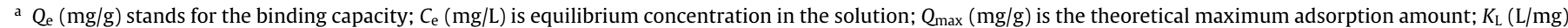
is the adsorption equilibrium constant.

b $K_{\mathrm{F}}$ is a Freundlich constant related to the adsorption capacity; $1 / n$ is a constant depicting the adsorption intensity or surface heterogeneity.

${ }^{c} K_{\mathrm{d}}(\mathrm{mg} / \mathrm{L})$ is the equilibrium dissociation constant.

supernatant solutions was determined after incubation. Selectivity experiments were conducted by using $17 \alpha-E_{2}, E_{3}$, and $E_{1}$ as the structural analogues. Each group of experiments was carried out three times in parallel.

\subsection{Photo-regulated uptake and release of the PM-MIMs}

Photo-regulated uptake and release of $17 \beta-\mathrm{E}_{2}$ and its analogues by the PM-MIMs were carried out by alternate irradiation with 365 and $440 \mathrm{~nm}$ light. A series of the PM-MIMs samples $(5.0 \mathrm{mg})$ were dispersed in the DMSO-ACN solutions $(15 \mathrm{~mL})$ containing analytes $(40 \mu \mathrm{M})$. The suspension solution was stirred in the dark for $12 \mathrm{~h}$, and the binding amounts of the analytes were determined by HPLC. For the photocontrolled release of $17 \beta-E_{2}, 17 \alpha-E_{2}, E_{1}$, and $E_{3}$, their respective solution was stirred and irradiated at $365 \mathrm{~nm}$ for $1 \mathrm{~h}$. The UV-vis spectra of the suspension solution were determined every $10 \mathrm{~min}$. After $2 \mathrm{~h}$ of UV light irradiation at $365 \mathrm{~nm}$, the UV light was switched off and the binding amounts of the analytes were determined by HPLC. And meanwhile, the PM-MIMs particles were separated by an external magnet to the vial's inner bottom and then were transferred to a new vial for recycle use (Fig. 1). For the photoregulated uptake of $17 \beta-E_{2}, 17 \alpha-E_{2}, E_{1}$, and $E_{3}$, irradiation with $440 \mathrm{~nm}$ was used for $1 \mathrm{~h}$. Besides, all procedures were similar to those in the release experiments.

\subsection{Analysis of $17 \beta-E_{2}$ in real samples by the PM-MIMs}

Milk powder and drinking water samples (2g) without spiking or spiked with $17 \beta-\mathrm{E}_{2}$ standard solutions ( $2 \mathrm{~mL} ; 0.2,0.5$, or $1.0 \mu \mathrm{moL})$ were firstly extracted using ACN $(20 \mathrm{~mL})$ for $30 \mathrm{~min}$. The extract solutions were obtained after centrifugation and filtration. The PM-MIMs (20 mg) were added to the extract solution, and then shaken at room temperature for $1 \mathrm{~h}$ in the dark with the help of $440 \mathrm{~nm}$ irradiation. The PM-MIMs were separated from the solu- 

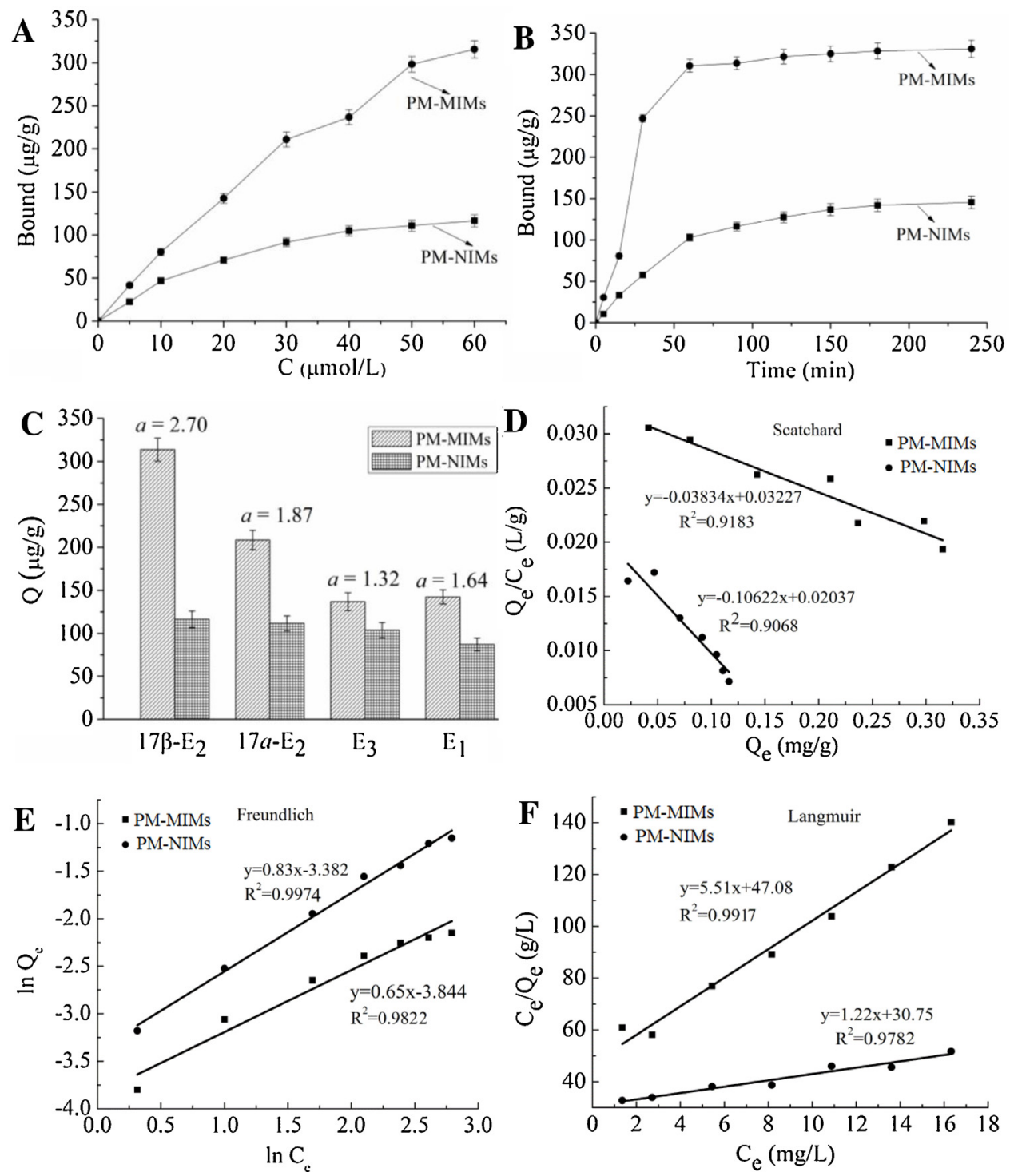

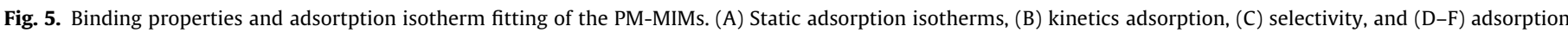
isotherm fitting models.

tion with an external magnet and the $17 \beta-\mathrm{E}_{2}$ in the supernatant was determined by HPLC. The binding of $17 \beta-\mathrm{E}_{2}$ on the PM-MIMs was subsequently eluted with DMSO/methanol (1:1, v:v) containing $0.5 \%$ acetic acid under irradiation at $365 \mathrm{~nm}$. The eluants were evaporated under nitrogen at $40^{\circ} \mathrm{C}$, and the residues were redissolved in DMSO-ACN solution $(1.0 \mathrm{~mL})$ for further HPLC analysis.

\section{Results and discussion}

\subsection{Preparation of PM-MIMs}

Fig. 1 schematically shows the preparation process of the PMMIMs by a seed polymerization method, possible mechanism of photoregulated uptake and release of template molecules from the PM-MIMs, and the whole procedure for extraction of $17 \beta-E_{2}$ from real samples using the PM-MIMs. As seen, superparamagnetic magnetic $\mathrm{Fe}_{3} \mathrm{O}_{4}$ nanoparticles were synthesized as the magnetic core for the PM-MIMs, making it easily be separated by the external magnetic field from solutions. For improving stability and preventing magnetic leaking, $\mathrm{Fe}_{3} \mathrm{O}_{4}$ nanoparticles were coated with $\mathrm{SiO}_{2}$, and then functionalized with $\mathrm{KH}_{570}$ for grafting of vinyl dou- ble bonds and thereby for further polymerizing with functional monomers easily. On the other hand, it is well known that light has lots of advantages, such as clean, safe, precise and remote controllable properties, which make photoresponsive materials have become the most popular intelligent materials. Among these photoresponsive materials, photoinduced trans-cis isomerization of azobenzene has become a research hotspot due to the geometry and dipole moment to the chromophore, which would be changed greatly under UV irradiation. Because of possessing a photoresponsive azobenzene chromphore (that is trans-cis and cis-trans photoisomerization at 365 and $440 \mathrm{~nm}$ irradiation, respectively), benzoic acid functionality, and a polymerizable methacryloyl group, self-synthesized MPABA was adopted as the photoresponsive functional monomer, and pre-assembled with template molecules $\left(17 \beta-\mathrm{E}_{2}\right)$ in the DMSO-ACN solution, and then the initiator and cross-linker were added into the DMSO-ACN solution and induced the polymerization on the functionalized $\mathrm{Fe}_{3} \mathrm{O}_{4}$ nanoparticle surface in the dark conditions (Fig. 1). After eluting $17 \beta-\mathrm{E}_{2}$, the resultant PM-MIMs rendered it to possess the properties of the azobenzene trans-cis photoisomerization and superparamagnetic susceptibility, as well as improved selectivity. Therefore, the 

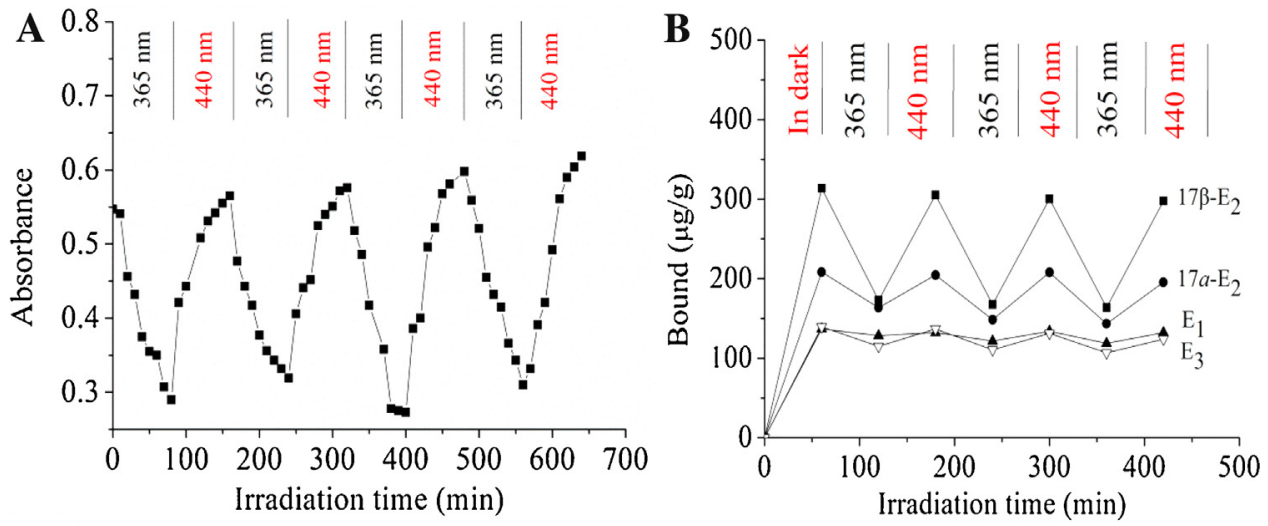

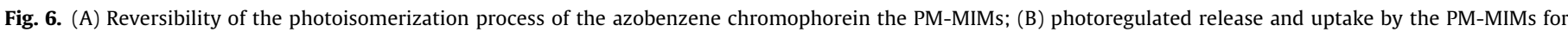
$17 \beta-E_{2}$ and its analogues.

PM-MIMs would occupy the ability to photoregulated uptake and release for template molecules under light-stimulation, and could be rapidly separated easily by the external magnetic field for recycle use, as schematically illustrated in Fig. 1.

\subsection{Characterization of the PM-MIMs}

The obtained PM-MIMs were fully characterized by TEM, VSM, $\mathrm{XRD}, \mathrm{TGA}$ and BET as follows. The morphological structures of the $\mathrm{Fe}_{3} \mathrm{O}_{4}, \mathrm{Fe}_{3} \mathrm{O}_{4} @ \mathrm{SiO}_{2}$, and PM-MIMs were observed by TEM (Fig. 2). It can be seen that $\mathrm{Fe}_{3} \mathrm{O}_{4}$ particles exhibited nearly spherical shape (Fig. 2A and $\mathrm{B}$ ) with polycrystalline-like diffraction ((Fig. 2A, inset), suggesting that each $\mathrm{Fe}_{3} \mathrm{O}_{4}$ particle was composed of many smaller magnetite nanoparticles. After $\mathrm{SiO}_{2}$ coating, the $\mathrm{Fe}_{3} \mathrm{O}_{4} @ \mathrm{SiO}_{2}$ coreshell material still remained spherical morphology (Fig. 2C). The dark $\mathrm{Fe}_{3} \mathrm{O}_{4}$ particles were individually coated with a uniform silica shell with the thickness of about $20 \mathrm{~nm}$ ((Fig. 2D). Silica layer not only made $\mathrm{Fe}_{3} \mathrm{O}_{4}$ surface modification easier and more effective, but also protected the magnetic cores from leaking and etching in the synthesized processes. As shown in Fig. 2E and F, the PM-MIMs displayed spherical microspheres with a sandwich structure, which was composed of a dark $\mathrm{Fe}_{3} \mathrm{O}_{4}$ core, a gray $\mathrm{SiO}_{2}$ middle layer, and a light-gray MIPs shell with the thickness of about $25 \mathrm{~nm}$. In addition, it is observed that the dispersibility of PM-MIMs is not good as $\mathrm{Fe}_{3} \mathrm{O}_{4}$ and $\mathrm{Fe}_{3} \mathrm{O}_{4} @ \mathrm{SiO}_{2}$, which is very likely based on the two reasons as follows. One is that the crosslinking substances containing double bonds could more easily form shell-layers on the surface of $\mathrm{Fe}_{3} \mathrm{O}_{4} @ \mathrm{SiO}_{2}$, and thereby result in aggregation to some extent. The other is that the PM-MIMs samples were not completely dried because of the compact structure after polymerization with cross-linkers, under the same TEM experimental conditions for the three materials, and thus a certain aggregation and conglutination occurred. Nevertheless, compared with traditional MIPs, such core-shell sandwich structure with thin imprinting shell was favorable to the fast mass transfer for template removing and rebinding, resulting in higher adsorption ability and imprinting efficiency.

The magnetic properties of $\mathrm{Fe}_{3} \mathrm{O}_{4}, \mathrm{Fe}_{3} \mathrm{O}_{4} @ \mathrm{SiO}_{2}$, and the PMMIMs were measured by VSM, and the corresponding magnetic hysteresis loops are shown in Fig. 3A. It is obvious that the remanence/coercivity of the $\mathrm{Fe}_{3} \mathrm{O}_{4}, \mathrm{Fe}_{3} \mathrm{O}_{4} @ \mathrm{SiO}_{2}$, and PM-MIMs almost disappeared with displaying superparamagnetic characteristics, suggesting that the PM-MIMs had ability of quick aggregation as well as homogeneous suspension. The saturation magnetization values of the $\mathrm{Fe}_{3} \mathrm{O}_{4}, \mathrm{Fe}_{3} \mathrm{O}_{4} @ \mathrm{SiO}_{2}$, and PM-MIMs were 53.62, 37.39, and $24.31 \mathrm{em} \mu \mathrm{g}^{-1}$, respectively. Such high saturation magneti- zation made the PM-MIMs is rapidly separated from solution by external magnetic field within about $30 \mathrm{~s}$. These unique magnetic properties ensured a rapid switch in the separation-redispersion process for the PM-MIMs, which would lead to the fast and efficient separation for template molecules from complicated samples with external magnetic field.

The typical XRD patterns of the $\mathrm{Fe}_{3} \mathrm{O}_{4}, \mathrm{Fe}_{3} \mathrm{O}_{4} @ \mathrm{SiO}_{2}$, and PM-MIMs were shown in Fig. 3B. The characteristic peaks of $\mathrm{Fe}_{3} \mathrm{O}_{4}\left(2 \theta=30.12,35.41,43.19,53.67,57.20\right.$, and $\left.62.71^{\circ}\right)$ were (2 20$),(311),(400),(422),(511)$, and (440), respectively, which matched well with the JSPDS card (No. 19-62-9). The broad diffraction peaks further confirmed the nanocrystalline structure of the magnetite particles. The intensity of the $\mathrm{Fe}_{3} \mathrm{O}_{4}$ characteristic peaks weakened after coating silica layers and MIPs shells, but the nanocrystalline crystal properties of magnetite particles were not destroyed during the synthesis and polymerization processes for the PM-MIMs.

The TGA results of the $\mathrm{Fe}_{3} \mathrm{O}_{4}, \mathrm{Fe}_{3} \mathrm{O}_{4} @ \mathrm{SiO}_{2}, \mathrm{Fe}_{3} \mathrm{O}_{4} @ \mathrm{SiO}_{2}-\mathrm{KH}_{570}$, and PM-MIMs were displayed in Fig. 3C. It showed that the TGA curve of $\mathrm{Fe}_{3} \mathrm{O}_{4}$ nanoparticles was almost a straight line without any impurities. The weight loss of $12.10 \%$ was found at about $700^{\circ} \mathrm{C}$ for the $\mathrm{Fe}_{3} \mathrm{O}_{4} @ \mathrm{SiO}_{2}$, which attributed to the dehydration of silica layer. The $\mathrm{Fe}_{3} \mathrm{O}_{4} @ \mathrm{SiO}_{2}-\mathrm{KH}_{570}$ exhibited bigger weight loss (5.79\%), which may be due to the pyrolysis of $\mathrm{KH}_{570}$. However, a dramatic weight loss (46.75\%) was found for the PM-MIMs at the beginning of $250^{\circ} \mathrm{C}$, and the weight kept relative constant until $700^{\circ} \mathrm{C}$, suggesting that the whole imprinted polymer layers on the $\mathrm{Fe}_{3} \mathrm{O}_{4} @ \mathrm{SiO}_{2}$ surface almost decomposed, and further confirming the successful polymerization of imprinted polymers on the $\mathrm{Fe}_{3} \mathrm{O}_{4} @ \mathrm{SiO}_{2}-\mathrm{KH}_{570}$ surface.

The nitrogen adsorption-desorption isotherms of the PM-MIMs and PM-NIMs were shown in Fig. 3D. Obviously, the type IV isotherm curve with a loop was observed for the PM-MIMs, suggesting that the PM-MIMs formed a well-defined porous structure after removing template molecules. However, the desorption curve was closer but slightly leveled above the adsorption curve for the PMMIMs, which indicated that the PM-MIMs were quite stable. The structure parameters of the PM-MIMs and PM-NIMs were obtained by BET analysis. The surface area and peak pore size of the PM-MIMs were $78.23 \mathrm{~m}^{2} \mathrm{~g}^{-1}$ and $8.36 \mathrm{~nm}$, respectively, while those parameters of the PM-NIMs were $33.66 \mathrm{~m}^{2} \mathrm{~g}^{-1}$ and $4.78 \mathrm{~nm}$, respectively. It can be seen that the surface area and peak pore size of the PM-MIMs were much larger than that of the PM-NIMs, which was very likely due to the formation of binding sites after removing of template molecules on the $\mathrm{Fe}_{3} \mathrm{O}_{4} @ \mathrm{SiO}_{2}-\mathrm{KH}_{570}$ surface. 
Table 2

Recoveries of $17 \beta-E_{2}$ in milk powder and drinking water samples by using the PM-MIMs with and without light irradiation. ${ }^{\mathrm{a}}$

\begin{tabular}{|c|c|c|c|c|c|}
\hline \multirow[t]{2}{*}{ Samples } & \multirow[t]{2}{*}{ Added ( $\mu \mathrm{moL})$} & \multicolumn{2}{|l|}{ PM-MIMs ${ }^{b}$} & \multicolumn{2}{|l|}{ PM-MIMs ${ }^{\mathrm{C}}$} \\
\hline & & Found $(\mu \mathrm{moL})$ & Recovery \pm RSD $^{\mathrm{d}}(\%)$ & Found ( $\mu \mathrm{moL})$ & Recovery \pm RSD (\%) \\
\hline Milk & 0.2 & 0.209 & $105.5 \pm 1.9$ & 0.056 & $27.5 \pm 7.9$ \\
\hline pow- & 0.5 & 0.494 & $98.8 \pm 3.1$ & 0.132 & $26.4 \pm 3.6$ \\
\hline der & 1.0 & 1.130 & $113.0 \pm 2.7$ & 0.296 & $29.6 \pm 1.3$ \\
\hline Drinking & 0.2 & 0.196 & $98.0 \pm 4.4$ & 0.050 & $25.0 \pm 7.6$ \\
\hline \multirow[t]{2}{*}{ water } & 0.5 & 0.502 & $100.4 \pm 2.8$ & 0.176 & $35.2 \pm 2.0$ \\
\hline & 1.0 & 0.975 & $97.5 \pm 2.2$ & 0.257 & $25.7 \pm 1.7$ \\
\hline
\end{tabular}

${ }^{\mathrm{a}}$ The milk powder and drinking water samples $(2 \mathrm{~g})$ spiked with $17 \beta-\mathrm{E}_{2}$ standard solutions $(2 \mathrm{~mL}, 0.2,0.5$, or $1.0 \mu \mathrm{moL})$.

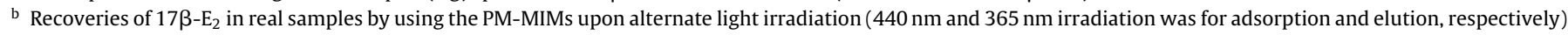

c Recoveries of $17 \beta-\mathrm{E}_{2}$ in real samples by using the PM-MIMs without light irradiation.

d Data were expressed as the mean \pm RSD determined from triplicate independent experiments.

Table 3

Performance comparison with other reported methods for $17 \beta-E_{2}$.

\begin{tabular}{|c|c|c|c|c|c|c|}
\hline Pretreatment method & Analytical system & Samples & Selective & Magnetic separation & Eluting method & Ref. \\
\hline $\mathrm{C}_{18}-\mathrm{SPE}$ & LC/MS/MS & Sewage & $\mathrm{N}^{\mathrm{a}}$ & $\mathrm{N}$ & $\mathrm{T}^{\mathrm{b}}$ & [9] \\
\hline Silica-SPE & HPLC/DAD & Water & $\mathrm{N}$ & $\mathrm{N}$ & $\mathrm{T}$ & [8] \\
\hline SPE & GC/MS & Egg; honey & $\mathrm{N}$ & $\mathrm{N}$ & $\mathrm{T}$ & [10] \\
\hline MIP-SPE & HPLC/UV & Fish & $\mathrm{Y}^{\mathrm{c}}$ & $\mathrm{N}$ & $\mathrm{T}$ & [14] \\
\hline MIP-SPE & HPLC/UV & Duck feed & Y & $\mathrm{N}$ & $\mathrm{T}$ & [15] \\
\hline MIP-SPE & HPLC/UV & Meat & Y & $\mathrm{N}$ & $\mathrm{T}$ & [18] \\
\hline MIP-SPE & HPLC/UV & Water; soil; yogurt & $\mathrm{Y}$ & $\mathrm{N}$ & $\mathrm{T}$ & [16] \\
\hline MIP-SPE & UV & Milk & $\mathrm{Y}$ & $\mathrm{Y}$ & $\mathrm{T}$ & [13] \\
\hline MIP-SPE & HPLC/UV & Water & $\mathrm{Y}$ & $\mathrm{Y}$ & $\mathrm{T}$ & [17] \\
\hline MIP-SPE & HPLC/UV & Milk powder; drinking water & $\mathrm{Y}$ & $\mathrm{Y}$ & $\mathrm{P}^{\mathrm{d}}$ & This work \\
\hline
\end{tabular}

a $\mathrm{N}$ is no.

b $\mathrm{T}$ is traditional eluting method, which needs a large amount organic solvent, heating and time consuming.

c $\mathrm{Y}$ is Yes.

d $\mathrm{P}$ is photo-irradiation eluting method, which is environmental-friendly, rapid and convenient.

\subsection{Photoisomerization property of the PM-MIMs}

MPABA was chosen as the photoresponsive functional monomer in our study because it possesses a photoresponsive azobenzene chromphore, benzoic acid functionality, and a polymerizable methacryloyl group. The photoisomerization properties of the MPABA and PM-MIMs were investigated by UV-vis upon alternate irradiation at 365 and $440 \mathrm{~nm}$, respectively. From the results of Fig. 4A, it can be found that the UV-vis spectra of the MPABA exhibited one strong absorption at about $333 \mathrm{~nm}$ under irradiating at $365 \mathrm{~nm}$, which was attribute to $\pi-\pi^{*}$ electron transition of the $\mathrm{N}=\mathrm{N}$ bond in azobenzene. The results also indicated that the intensity of $\pi-\pi^{*}$ transition decreased rapidly and reached photo-stationary state after $90 \mathrm{~min}$ at $365 \mathrm{~nm}$ irradiation, which was due to the transcis photoisomerization of the azobenzene. However, the intensity of the $\pi-\pi^{*}$ transition increased when irradiation at $440 \mathrm{~nm}$ due to the reverse cis-trans photoisomerization of the azobenzene (Fig. 4B). After polymerization on the $\mathrm{Fe}_{3} \mathrm{O}_{4} @ \mathrm{SiO}_{2}-\mathrm{KH}_{570}$ surface, the azobenzene chromophores of the MPABA still remained the photoresponsive properties. But the trans-cis and cis-trans isomerization intensities of the azobenzene chromophores within the PM-MIMs were lower than that of the pure MPABA (Fig. 4C and D), suggesting that the photoisomerization ability of the azobenzene chromophores decreased. The decreasing was very likely owing to that the rigid environment of the polymer matrix hindered the reorientation of the azobenzene chromophores [27]. The reversible photoinduced isomerization property of the PM-MIMs would improve adsorption or release ability for template molecules upon proper photoirradiation. Thus, such photo-responsive property of the PM-MIMs could decrease/eliminate the use of a large amount of organic solvents commonly used for elution by traditional MIPs, and offered rapidity, simplicity, cost-saving and environmental friendliness.

\subsection{Binding properties of the PM-MIMs}

The binding properties of the PM-MIMs played key roles in possible practical applications, which were investigated by performing the static, kinetic and selectivity studies. Fig. 5A displays the static adsorption isotherm of $17 \beta-\mathrm{E}_{2}$ by the PM-MIMs. The results suggested that the binding capacity for $17 \beta-\mathrm{E}_{2}$ increased quickly at first and then slowed down with its initial concentration increasing. The adsorption amount became stable and reached equilibrium at $60 \mu \mathrm{mol} \mathrm{L}^{-1}$ with binding capacity of $315.6 \pm 10.1 \mu \mathrm{gg}^{-1}$, suggesting that the recognition sites were almost completely occupied by the template molecules. Results also showed that the PMNIMs exhibited the same trend as the PM-MIMs but with lower binding capacity, probably due to the absence of specific binding sites in them. In order to further evaluate the molecular binding properties of the PM-MIMs, Scatchard, Freundlich, and Langmuir isotherms were applied to fit these static adsorption data, as show in Fig. 5D-F, respectively. It can be seen that the maximal adsorption capacity $\left(Q_{\max }\right)$ and equilibrium dissociation constant $\left(K_{\mathrm{d}}\right)$ were $842.0 \mu \mathrm{g} \mathrm{g}^{-1}$ and $26.1 \mathrm{mg} \mathrm{L}^{-1}$ for the PM-MIMs according to the Scatchard equation, respectively, as listed in Table 1. Notably, the Freundlich isotherm model was more suitable to describe the static adsorption with the highest correlation coefficient $\left(R^{2}=0.9974\right)$.

The absorption kinetics results were shown in Fig. 5B. It can be see that the binding amounts of $17 \beta-\mathrm{E}_{2}$ on the PM-MIMs increased rapidly before $30 \mathrm{~min}$, and reached equilibrium after $60 \mathrm{~min}$ with binding amount of $310.6 \pm 12.6 \mu \mathrm{gg}^{-1}$. It is clearly seen that the surface imprinting method for the PM-MIMs showed shorter equilibrium time, which could be attributed to the fact that the thin imprinted layer on the PM-MIMs surface made the imprinted sites more accessible, faster mass transfer, easier binding and completely removing of template molecules. In addition, the binding capacity of PM-MIMs was much higher than that of the PM-NIMs 
$\left(102.9 \pm 7.2 \mu \mathrm{gg}^{-1}\right)$, suggesting uniform spherical structure and larger specific surface area of the PM-MIMs were beneficial to rapid mass transfer.

The structurally similar compounds $\left(17 \alpha-E_{2}, E_{3}\right.$, and $\left.E_{1}\right)$ were chosen as the structural analogues for the selective recognition study. As seen from Fig. 5C, the PM-MIMs exhibited higher binding capacity for $17 \beta-\mathrm{E}_{2}$ than that for these structural analogues. The binding capacities of the PM-MIMs for $17 \beta-E_{2}, 17 \alpha-E_{2}$, $E_{3}$, and $E_{1}$ were $313.7 \pm 13.5,208.8 \pm 11.3,136.8 \pm 10.4$, and $142.3 \pm 8.8 \mu \mathrm{g} \mathrm{g}^{-1}$, respectively, suggesting that the PM-MIMs had higher selectivity for $17 \beta-\mathrm{E}_{2}$. Fig. $5 \mathrm{C}$ also shows that the binding amount of the PM-NIMs was lower than that of the PM-MIMs and nonselective for these structurally similar compounds. Correspondingly, the imprinted factor $(\alpha)$ values of $17 \beta-E_{2}, 17 \alpha-E_{2}$, $E_{3}$, and $E_{1}$ were $2.70,1.87,1.32$, and 1.64 , respectively. These facts proved that a strong interaction between $17 \beta-\mathrm{E}_{2}$ and MPABA appeared, and then high-affinity and template-specific binding sites were formed on the PM-MIMs.

\subsection{Photo-regulated uptake and release of $17 \beta-E_{2}$ by the PM-MIMs}

Photoisomerization reversibility of azobenzene chromophores was the key factor for the PM-MIMs, which was investigated by alternate irradiation at 365 and $440 \mathrm{~nm}$, respectively. As shown in Fig. 6A, the photoisomerization of azobenzene chromophores in the PM-MIMs was reversible with no apparent photoreversibility losing after 4 cycles. However, the absorbance of azobenzene chromophores in the PM-MIMs gradually increased after each photoisomerization cycle, which may be due to the enlargement of the imprinted binding sites during the isomerization process.

Photoregulated release and uptake of $17 \beta-\mathrm{E}_{2}$ by the PM-MIMs were carried out under alternate irradiation at $365 \mathrm{~nm}$ and $440 \mathrm{~nm}$, and the results were shown in Fig. 6B. $140.9 \mu \mathrm{g} \mathrm{g}^{-1}$ (44.9\%) of $17 \beta-$ $\mathrm{E}_{2}$ released from the PM-MIMs with the irradiation at $365 \mathrm{~nm}$ for $1 \mathrm{~h}$, which could be attributed to the photoinduced trans-cis isomerization of azobenzene chromophores in the recognition cavities, leading to a change in the recognition cavities and thereby weaken the interaction between the MPABA and $17 \beta-\mathrm{E}_{2}$, thus the $17 \beta-\mathrm{E}_{2}$ bound was released back into the solution. On the contrary, the released amounts for $17 \beta-E_{2}$ of $123.5 \mu \mathrm{g} \mathrm{g}^{-1}$ (94.02\%) rebound into the PM-MIMs after irradiation at $440 \mathrm{~nm}$ for another $1 \mathrm{~h}$, which was due to the cis-trans isomerization of azobenzene chromophores, resulting in the receptor-site configuration and substrate affinity reversible to original, and were complementary to $17 \beta-\mathrm{E}_{2}$ in shape, size and chemical functionality again. Repeating the photoswitching irradiation resulted in the release and uptake of $17 \beta-\mathrm{E}_{2}$ in nearly similar amounts to the previous cycle, suggesting that the binding site configuration and substrate affinity were reversible during the course of photoswitching of azobenzene chromophores. In contrast, the changes of release and uptake amounts were not obvious for these structural analogues under the same conditions (Fig. 6B), suggesting the PM-MIMs had highly selective photoresponsive ability towards $17 \beta-\mathrm{E}_{2}$.

\subsection{Reusability of the PM-MIMs}

As we all know, reusability is an important index for the MIPs materials, which is undoubted a key factor in improving the economic efficiency and extending their applications. To investigate the reusability, the PM-MIMs samples $(5.0 \mathrm{mg})$ were dispersed in $17 \beta-E_{2}$ solutions $(40 \mu \mathrm{M})$ under $440 \mathrm{~nm}$ irradiation for $1 \mathrm{~h}$. Afterwards, the PM-MIMs samples were separated by external magnet and then the $17 \beta-E_{2}$ molecules were eluted with DMSO/methanol $(1: 1, v: v)$ containing $0.5 \%$ acetic acid under irradiation at $365 \mathrm{~nm}$.
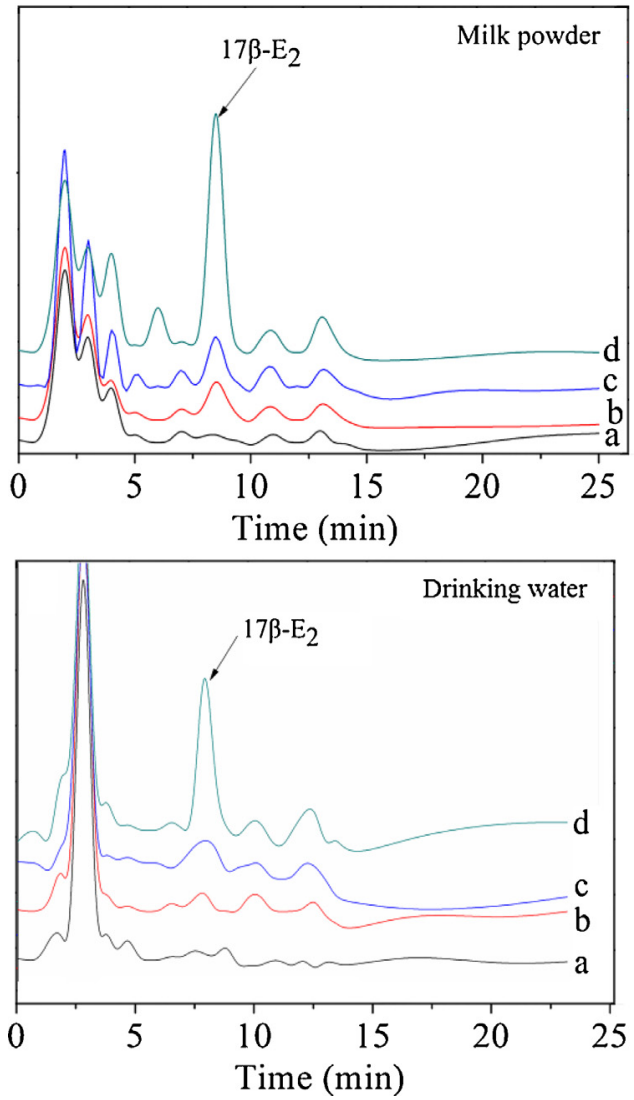

Fig. 7. HPLC-UV chromatograms of milk powder and drinking water samples: (a) samples without spiked, (b) spiked samples without the PM-MIMs extraction, (c) spiked sample with the PM-MIMs extraction in dark without irradiation, and (d) spiked sample with the PM-MIMs extraction under corresponding photoirradiation.

Subsequently, the adsorption capacities of the $17 \beta-\mathrm{E}_{2}$ were determined by HPLC method. Such adsorption-desorption processes of the same PM-MIMs were carried out for five cycles. Accordingly, the recoverability of the five cycles presented the relative standard deviations (RSDs) less than 4.5\%, suggesting that the PM-MIMs were excellently reusable. Meanwhile, the PM-MIMs could be separated rapidly within $5 \mathrm{~min}$ under external magnet. These results indicated that the PM-MIMs could be could be used repeatedly without significant decrease in their adsorption capacities for $17 \beta-\mathrm{E}_{2}$ with simple magnetic separation and eco-friendly template elution.

\subsection{Application of the PM-MIMs to real samples}

In order to evaluate the practical applicability, the PM-MIMs were used to enrich and elute $17 \beta-\mathrm{E}_{2}$ with and without light irradiation from milk powder and drinking water samples, respectively. The elutions were determined by HPLC and the results were shown in Fig. 7. As seen, no $17 \beta-E_{2}$ was detected $g$ for the blank samples (Fig. 7a), and a small peak appeared after $17 \beta-E_{2}$ spiking without the PM-MIMs extraction (Fig. 7b). Then, the PMMIMs were used in dark without any irradiation, only a small peak of $17 \beta-E_{2}$ was found under such conditions (Fig. 7c). However, excitingly, a significantly increased peak of $17 \beta-E_{2}$ appeared after the PM-MIMs pretreatment under corresponding photo-irradiation (Fig. 7d). Their corresponding recoveries and RSD results are listed in Table 2, presenting high recoveries of $97.5-113.0 \%$ with low RSD less than $4.4 \%$ using photo-irradiation. At the same conditions, favorable limit of detection ( $\mathrm{LOD}, \mathrm{S} / \mathrm{N}=3$ ) and limit of quantification (LOQ $S / N=10$ ) for $17 \beta-E_{2}$ were attained of 0.18 and $0.62 \mu \mathrm{mol} \mathrm{L}^{-1}$, 
respectively. However, the remarkably decreased recoveries of 25.0-35.2\% were observed without photo irradiation for the PMMIMs (Table 2). These results showed that the proper irradiation conditions could improve the adsorption and release ability for the PM-MIMs. Compared with some traditional pretreatment methods [8-10,13-18], as listed in Table 3, the PM-MIMs demonstrated excellent properties such as high selectivity, fast binding kinetics, easy separation, and especially the smart elution/adsorption mode of stimuli-regulated adsorption and release for template molecules.

\section{Conclusions}

In conclusion, photonic response, magnetic separation and surface imprinting were reasonably combined for smart material preparation and then were applied to fast and selective extraction of $17 \beta-E_{2}$. The resultant PM-MIMs displayed spherical sandwich structure with $\mathrm{Fe}_{3} \mathrm{O}_{4}$ core, a gray $\mathrm{SiO}_{2}$ middle layer, and photoresponsive MIPs shell. The PM-MIMs exhibited photoresponsive and magnetic properties with specific recognition, high binding capacity, and fast binding kinetics. High recoveries in spiked milk power and drinking water samples proved that the PM-MIMs were feasible materials for rapid enrichment and separation of $17 \beta-E_{2}$ from complicated matrices under proper irradiation conditions. The PM-MIMs not only had the ability to photoregulated uptake and release of template molecules, but also could be separated quickly from solutions by external magnet. These results also indicated that the processes of enrichment, separation, and release for $17 \beta-E_{2}$ can be recycled with advantages of convenience, rapidity, cost/labor-effectiveness and eco-friendliness. Furthermore, the PM-MIMs based method provided a potential new strategy for EEs pollution monitoring and abatement/remediation, and pushed forward the development of versatile SR-MIPs for potential applications.

\section{Acknowledgments}

This work was financially supported by the National Natural Science Foundation of China (21477160 and 21366019), the Natural Science Foundation of Jiangxi Province (20142BAB213003 and 20151BAB203029), and International Science and Technology Cooperation Program of China (2011DFA32770).

\section{References}

[1] S.K. Khanal, B. Xie, M.L. Thompson, S. Sung, S.K. Ong, J. Leeuwen, Fate transport, and biodegradation of natural estrogens in the environment and engineered systems, J. Environ. Sci. 40 (2006) 6537-6546.

[2] S. Narita, R.M. Goldblum, C.S. Watson, E.G. Brooks, D.M. Estes, E.M. Curran, T. Midoro-Horiuti, Environmental estrogens induce mast cell degranulation and enhance IgE-mediated release of allergic mediators, Environ. Health Perspect. 115 (2007) 48-52.

[3] S. Sangsritavong, D.K. Combs, R. Sartori, L.E. Armentano, M.C. Wiltbank, High feed intake increases liver blood flow and metabolism of progesterone and estradiol-17ß in dairy cattle, J. Dairy Sci. 85 (2002) 2831-2842.

[4] C. Buisson, M. Hebestreit, A.P. Weigert, K. Heinrichd, H. Fryc, U. Flenker, S. Banneke, S. Prevost, F. AnP. Me, W. Schaenzer, E. Houghton, B. Bizec, Application of stable carbon isotope analysis to the detection of 17-estradiol administration to cattle, J. Chromatogr. A 1093 (2005) 69-80.

[5] H.M. Kuch, K. Ballschmiter, Determination of endocrine-disrupting phenolic compounds and estrogens in surface and drinking water by HRGC-(NCI)-MS in the picogram per liter range, Environ. Sci. Technol. 35 (2001) 3201-3206.

[6] J. Kaiser, Panel cautiously confirms low-dose effects, Science 290 (2000) 695

[7] T. Tanaka, H. Takeda, F. Ueki, K. Obata, H. Tajima, H. Takeyama, Y. Goda, S. Fujimoto, T. Matsunaga, Rapid and sensitive detection of 17-estradiol in environmental water using automated immunoassay system with bacterial magnetic particles, J. Biotechnol. 108 (2004) 153-159.

[8] J. Gañán, D. Pérez-Quintanilla, S. Morante-Zarcero, I. Sierra, Comparison of different mesoporous silicas for off-line solid phase extraction of $17 \beta$-estradiol from waters and its determination by HPLC-DAD, J. Hazard. Mater. 260 (2013) 609-617.

[9] T. Vega-Morales, Z. Sosa-Ferrera, J. Santana-RoP. Míguez, Determination of alkylphenol polyethoxylates bisphenol-A, 17-ethynylestradiol and 17-estradiol and its metabolites in sewage samples by SPE and LC/MS/MS, J Hazard. Mater. 183 (2010) 701-711.

[10] A. Azzouz, E. Ballesteros, Multiresidue method for the determination of pharmacologically active substances in egg and honey using a continuous solid-phase extraction system and gas chromatography-mass spectrometry, Food Chem. 178 (2015) 63-69.

[11] L.X. Chen, S.F. Xu, J.H. Li, Recent advances in molecular imprinting technology: current status, challenges and highlighted applications, Chem. Soc. Rev. 40 (2011) 2922-2942

[12] L.X. Chen, X.Y. Wang, W.H. Lu, X.Q. Wu, J.H. Li, Molecular imprinting: perspectives and applications, Chem. Soc. Rev. (2016), http://dx.doi.org/10. 1039/c6cs00061d.

[13] F.J. Ning, H.L. Peng, J.H. Li, L.X. Chen, H. Xiong, Molecularly imprinted polymer on magnetic graphene oxide for fast and selective extraction of $17 \beta$-Estradiol, J. Agric. Food Chem. 62 (2014) 7436-7443.

[14] T.H. Jiang, L.X. Zhao, B.L. Chu, Q.Z. Feng, W. Yan, J.M. Lin, Molecularly imprinted solid-phase extraction for the selective determination of $17 \beta$-estradiol in fishery samples with high performance liquid chromatography, Talanta 78 (2009) 442-447.

[15] J. Ma, L.H. Yuan, M.J. Ding, S. Wang, F. Ren, J. Zhang, S.H. Du, F. Li, X.M. Zhou, The study of core-shell molecularly imprinted polymers of $17 \beta$-estradiol on the surface of silica nanoparticles, Biosens. Bioelectron. 26 (2011) 2791-2795

[16] J.H. Li, R.C. Dong, X.Y. Wang, H. Xiong, S.F. Xu, D.Z. Shen, X.L. Song, L.X. Chen, One-pot synthesis of magnetic molecularly imprinted microspheres by RAFT precipitation polymerization for the fast and selective removal of 17ß-estradiol, RSC Adv. 5 (2015) 10611-10618.

[17] Y. Hao, R.X. Gao, L. Shi, D.C. Liu, Y.H. Tang, Z.J. Guo, Water-compatible magnetic imprinted nanoparticles served as solid-phase extraction sorbents for selective determination of trace 17 beta-estradiol in environmental water samples by liquid chromatography, J. Chromatogr. A 29 (2015) 7-16.

[18] S. Yun, P.D. Dong, S.C. Hua, Z. Xia, X.Y. Ting, Selective determination of trace $17 \beta$-estradiol in dairy and meat samples by molecularly imprinted solid-phase extraction and HPLC, Food Chem. 126 (2011) 1916-1925.

[19] R.X. Gao, X.H. Cui, Y. Hao, L.L. Zhang, D.C. Liu, Y.H. Tang, A highly-efficient imprinted magnetic nanoparticle for selective separation and detection of 17ß-estradiol in milk, Food Chem. 194 (2016) 1040-1047.

[20] R.X. Gao, Y. Hao, S.Q. Zhao, L.L. Zhang, X.H. Cui, D.C. Liu, Y.H. Tang, Y.S. Zheng, Novel magnetic multi-template molecularly imprinted polymers for specific separation and determination of three endocrine disrupting compounds simultaneously in environmental water samples, RSC Adv. 4 (2014) 56798-56808.

[21] H. Meng, G.Q. Li, A review of stimuli-responsive shape memory polymer composites, Polymer 54 (2013) 2199-2221

[22] S.F. Xu, H.Z. Lu, X.W. Zheng, L.X. Chen, Stimul-responsive molecularly imprinted polymers: versatile functional materials, J. Mater. Chem. C 1 (2013) 4406-4422.

[23] R.A. Lorenzo, A.M. Carro, A. Concheiro, C. Alvarez-Lorenzo, Stimuli-responsive materials in analytical separation, Anal. Bioanal. Chem. 407 (2015) 4927-4948.

[24] Y. Kanekiyo, R. Naganawa, H. Tao, pH-responsive molecularly imprinted polymers, Angew. Chem. Int. Ed. 42 (2003) 3014-3016.

[25] R.C. Dong, J.H. Li, H. Xiong, W.H. Lu, H.L. Peng, L.X. Chen, Thermosensitive molecularly imprinted polymers on porous carriers: preparation, characterization and properties as novel adsorbents for bisphenol A, Talanta 130 (2014) 182-191.

[26] Q.P. You, Y.P. Zhang, Q.W. Zhang, J.F. Guo, W.H. Huang, S.Y. Shi, X.Q. Chen, High-capacity thermo-responsive magnetic molecularly imprinted polymers for selective extraction of curcuminoids, J. Chromatogr. A 1354 (2014) 1-8.

[27] Z.Y. Li, H.J. Quan, C.B. Gong, Y.Z. Yang, Q. Tang, Y.B. Wei, X.B. Ma, H. Lam, Photocontrolled solid-phase extraction of guanine from complex samples using a novel photoresponsive molecularly imprinted polymer, Food Chem. 172 (2015) 56-62.

[28] C.B. Gong, K.L. Wong, M.H. Lam, Photoresponsive molecularly imprinted hydrogels for the photoregulated release and uptake of pharmaceuticals in the aqueous media, Chem. Mater. 20 (2008) 1353-1358.

[29] Y.H. He, Y.Y. Huang, Y.L. Jin, X.J. Liu, G.Q. Liu, R. Zhao, Well-defined nanostructured surface-imprinted polymers for highly selective magnetic separation of fluoroquinolones in human urine, ACS Appl. Mater. Interfaces 6 (2014) 9634-9642

[30] H. Li, L.Y. Wang, Highly selective detection of polycyclic aromatic hydrocarbons using multifunctional magnetic-luminescent molecularly imprinted polymers, ACS Appl. Mater. Interfaces 5 (2013) 10502-10509.

[31] C.B. Gong, M.H.W. Lam, H.K. Yu, Fabrication of a photoresponsive molecularly imprinted polymer for the photoregulated uptake and release of caffeine, Adv. Funct. Mater. 16 (2006) 1759-1767.

[32] Q. Tang, C.B. Gong, M.H.W. Lam, X.K. Fu, Preparation of a photoresponsive molecularly imprinted polymer containing fluorine-substituted azobenzene chromophores, Sensor. Actuat. B 156 (2011) 100-107.

[33] D.S. Wang, X.X. Zhang, S.Q. Nie, W.F. Zhao, Y. Lu, S.D. Sun, C.S. Zhao, Photoresponsive surface molecularly imprinted poly(ether sulfone) microfibers, Langmuir 28 (2012) 13284-13293.

[34] X.J. Li, S.A. Zhong, C.E. Li, Synthesis of novel photoresponsive molecularly imprinted polymer microspheres with special binding properties, J. Appl. Polym. Sci. 2 (2013) 869-876.

[35] C. Gomy, A.R. Schmitzer, Synthesis and photoresponsive properties of a molecularly imprinted polymer, Org. Lett. 9 (2005) 3865-3868. 
[36] Q. Tang, Y.T. Nie, C.B. Gong, C.F. Chow, J.D. Peng M.H.W. Lam, Photo-responsive molecularly imprinted hydrogels for the detection of melamine in aqueous media, J. Mater. Chem. 22 (2012) 19812-19820.

[37] Y.Z. Yang, Q. Tang, C.B. Gong, X.B. Ma, J.D. Peng, M.H.W. Lam, Ultrasensitive detection of bisphenol A in aqueous media using photoresponsive surface molecular imprinting polymer microspheres, N. J. Chem. 38 (2014) $1780-1788$.

[38] Y. Ma, Y. Zhang, M. Zhao, X. Guo, H. Zhang, Efficient synthesis of narrowly dispersed molecularly imprinted polymer microspheres with multiple stimuli-responsive template binding properties in aqueous media, Chem. Commun. 48 (2012) 6217-6219.
[39] Y.H. Deng Y. Cai, Z.K. Sun, J. Liu, C. Liu, J. Wei, W. Li, C. Liu, Y. Wang, D.Y. Zhao, Multifunctional mesoporous composite microspheres with well-designed nanostructure: a highly integrated catalyst system, J. Am. Chem. Sci. 132 (2010) 8466-8473.

[40] S.F. Xu, J.H. Li, X.L. Song, J.S. Liu, H.Z. Lu, L.X. Chen, Photonic and magnetic dual responsive molecularly imprinted polymers: preparation, recognition characteristics and properties as a novel sorbent for caffeine in complicated samples, Anal. Methods 5 (2013) 124-133. 